Jurnal Pujangga Volume 6, Nomor 2, Desember 2020

ISSN P 2443-1478

ISSN E 2443-148

\title{
POLA TUTUR PERLOKUSI DALAM WEB SERIES DI BALIK HATI: SEBUAH TNJAUAN PRAGMATIK PERSPEKTIF LEECH
}

\author{
Muhdie Amir Karim \\ Universitas Islam Negeri Sunan Kalijaga Yogyakarta \\ 082240685899 \\ muhdieamirk@gmail.com \\ Ifi Erwhintiana \\ Fakultas Adab dan Ilmu Budaya, \\ Universitas Islam Negeri Sunan Kalijaga Yogyakarta \\ 089634639644 \\ ifierwhintiana@gmail.com
}

Received Nov 12, 2020, Revised Nov 30, 2020 , Approved Dec 01, 2020

\begin{abstract}
The aim of this study is to analyze the types of perlocutionary act in Di Balik Hati web series. According to Geoffrey Leech's perspective, there are sixteen types of perlocutionary act. The types is used to analyze the dialogue of Di Balik Hati web series. This study is descriptive-qualitative. The sources of data from dialogues in the nine episodes of this web series. The technique of data collection is wactching and noting. And then, the technique of data analysis is model analisis Miles and Huberman. The types of perlocutionary acts found in this web series are 23 dialogues including: persuade, impress, get hearer to do, get hearer to know or learn, get hearer to think about, distract attention, irritate, deceive, inspire, encourage, and relieve tension
\end{abstract}

Keywords: leech, perlocutionary, web series

\begin{abstract}
ABSTRAK
Tujuan dari penelitian ini untuk menganalisis jenis-jenis tindak tutur perlokusi dalam web series Di Balik Hati. Menurut Geofrrey Leech terdapat 16 klasifikasi tindak tutur perlokusi. Pembagian tersebut digunakan untuk menganalisis ujaran dalam web series Di Balik Hati. Penelitian ini menggunakan metode deskriptif-kualitatif. Sumber data berasal dari ujaran-ujaran tokoh dalam 9 episode web series tersebut. Tehnik pengumpulan data dilakukan dengan menonton dan mencatat. kemudian tehnik analisis data menggunakan model analisis Miles dan Huberman. Adapun hasil penelitian ini ditemukan 23 tindak tutur perlokusi yang meliputi tuturan membujuk, mengesankan, membuat petutur melakukan sesuatu, membuat penutur tahu, membuat petutur berfikir akan sesuatu, mengalihkan perhatian, menjengkelkan atau menyakitkan, menipu, mengilhami, mendorong dan meredakan ketegangan.
\end{abstract}

Kata kunci: leech, perlokusi, web series 
ISSN P 2443-1478

ISSN E 2443-148

\section{Latar Belakang}

Dewasa ini sangat marak dengan pertontonan web series atau serial web. Korea Selatan berhasil menjadi sorotan para penikmat web series, pasalnya Korea Selatan dapat menyajikan web series dengan begitu apik dan menarik. Namun akhir-akhir ini, pengguna internet di Indonesia semakin menunjukkan perkembangannya, itu artinya kita telah hidup di zaman digital. Dengan dilihatnya peluang tersebut oleh para kreator konten, mereka berinisiai membuat sebuah tayangan film berdurasi lebih pendek dari umumnya dan hanya tayang di web maupun di youtube.

Dalam laman kompas.com, tercantum sebanyak 171 juta orang indonesia telah terhubung ke internet saat ini. Laporan tersebut didapat dari Asosiasi Penyelenggara Jasa Internet Indonesia (APJII) dalam laporan terbarunya (Pratomo, 2019). Terkait dengan jumlah penikmat internet di Indonesia yang tidak sedikit, terkhusus yang mengakses youtube, banyak yang mengatakan bahwasanya "youtube lebih dari tv". Pendapat tersebut adalah benar adanya. Menurut sebagian orang, apa yang ingin kita lihat sekarang bisa dilihat sekarang, itulah youtube. Apalagi tabiat manusia adalah ketidak cenderungan dalam menunggu, sama halnya dalam pertontonan antara tv dan youtube. Youtube menyajikan tayangan iklan lebih singkat serta bisa dilewati (skip), tidak perlu menunggu lama untuk menikmati sebuah tayangan.

Pengulangan konten pun menjadi perhitungan bagi warganet. Oleh sebab itu, salah satu dari sekian jawaban mengapa youtube lebih dari tv adalah dapat di ulang-ulangnya konten yang ditonton. Sementara tv? Tidak bisa, karena memiliki jadwal tayang sendiri. Dengan begitu, pada saat ingin menonton tv, kita harus mengikuti jadwal tayang. Sementara menonton youtube, ketika video dipublikasikan, kita bebas dapat menonton kapan saja, tanpa peduli jadwal.

Dalam hal ini, web series sendiri dapat dilihat kapanpun saja di youtube serta situs yang menyediakan layanan streaming video. Web series adalah tontonan film berepisode dan berdurasi lebih pendek dari sinetron (Erlangga, 2014). Kerap kali web series dapat menggantikan film layar lebar karna apa yang disajikan didalamnya tak kalah menarik. Disamping itu, akses yang mudahpun membuat youtube banyak digandrungi pengguna internet. Karena tidak semua orang memiliki tv, namun hampir setiap orang memiliki telepon seluler bahkan laptop, untuk dapat kapanpun dan dimanapun mengakses video.

Sebuah web series bertajuk dakwah, yang diproduksi oleh Film Maker Muslim, yang berjudul "Di Balik Hati" yang terdiri dari 9 episode berhasil menarik hati penikmat web series Islami, dapat dibuktikan melalui komentar-komentar yang bersifat memuji dan jumlah viewers 
Jurnal Pujangga Volume 6, Nomor 2, Desember 2020

ISSN P 2443-1478

ISSN E 2443-148

yang mencapai ratusan ribu. Web series ini dipublikasikan setelah FMM mempublikasikan banyak web series sebelumnya seperti Mahar Cinta, Cinta Fisabilillah, Ramadhan Cinta dan masih banyak lagi.

Didalam web series tersebut mengisahkan tentang seorang perempuan shalihah yang baik secara dhahir maupun batin. Ia bernama "Ana", yang selama hidupnya sebenarnya memiliki banyak kesempatan untuk melakukan dosa namun ia memilih untuk tidak melakukannya, ialah satu-satunya perempuan yang dapat melihat Abyad (setan penggoda umat yang taat). Berkenaan dengan nama Abyad, dalam episode ke 9 dijelaskan, bahwasanya Abyad bukanlah sebuah nama, namun gelar yang diberikan Iblis kepada pengikutnya yang bertugas untuk menggoda orang-orang sholeh. Kebersamaan Ana bersama Abyad lambat laun membuat Ana mengetahui bagaimana setan dapat mengelabui manusia dan bagaimana siasat setan dalam memperdayai manusia yang taat sekalipun.

Dalam tayangan web series tersebut tak dapat dipungkiri kaitannya dengan aspek komunikasi, dengan komunikasilah nilai-nilai dan pesan yang terdapat dalam sebuah karya akan tersampaikan. Menurut Dardjowojojo (2008), komunikasi adalah suatu sistem simbol lisan yang sifatnya arbiter yang mana dapat digunakan oleh suatu komunitas masyarakat dalam berinteraksi sesama anggotanya. Para pemeran dalam web series ini saling bertutur satu sama lain mengutarakan keinginan dan maksud tertentu. Berhubungan dengan hal itu, Searle mengemukaan ada tiga jenis tindakan yang dapat diwujudkan oleh seorang penutur secara pragmatis, yaitu tindak tutur lokusi (lucutionary act), tindak tutur ilokusi (ilocutionary act), dan tindak tutur perlokusi (perlocutionary act) (Wijana, Dewa Putu dan Rohmadi, 2011).

Penelitian ini bukanlah penelitian yang baru. Berdasarkan penelusuran peneliti, sudah ada beberapa penelitian terdahulu yang bisa digunakan sebagai tinjauan pustaka di dalam melakukan penelitian ini. Pertama, E. Zaenal Arifin. (2018). "Beragam Tuturan Dalam Pembicaraan Seharihari: Suatu Tinjauan Etnografi Komunikasi”. Penelitian ini bertujuan untuk menginventarisasi berbagai tuturan dalam berkomunikasi. Hasil penelitian menunjukan bahwa dalam pembicaraan sehari-hari kita menggunakan berbagai tuturan, seperti pendapat pakar pragmatik Austin, yakni: verdiktif, eksersitif, komisif, behabitif, dan ekspositif. Adapun jika berdasarkan teori Searle, tuturan pembicaraan manusia meliputi aserif, direktif, komisif, ekspresif, dan deklaratif (Arifin, 2018).

Kedua, Bambang Widiatmoko \& Waslam. (2017). Berjudul "Interjeksi Dalam Bahasa Indonesia: Analisis Pragmatik”. Penelitian ini bertujuan untuk mengetahui dan menjelaskan faktor 
Jurnal Pujangga Volume 6, Nomor 2, Desember 2020

ISSN P 2443-1478

ISSN E 2443-148

utama pembentukan interjeksi dalam bahasa Indonesia. Adapun hasil dari penelitian ini menunjukkan bahwa faktor utama pembentukan interjeksi dalam bahasa Indonesia adalah faktor makna kata/makna satuan bahasa dan situasi bicara (Widiatmoko, 2017).

Berdasarkan penjelasan yang tertera pada latar belakang di atas, penelitian ini hanya berfokus pada bentuk tindak tutur perlokusi, serta peneliti bermaksud untuk menjelaskan bentuk tindak tutur perlokusi didalam web series "Dibalik Hati".

\section{Rumusan Masalah}

Berdasarkan penjelasan yang tertera pada latar belakang diatas, maka penulis merumuskan pemasalahan dalam penelitian adalah Apa bentuk tindak tutur perlokusi di dalam web series "Di Balik Hati"?

\section{Tujuan Penelitian}

Adapun tujuan dalam penelitian ini adalah untuk mengetahui bentuk tindak tutur perlokusi yang terdapat didalam web series "Di Balik Hati".

\section{Tinjauan Pustaka}

\section{Tindak Tutur Perlokusi}

Dalam buku "Pragmatik Sebuah Perspektif Multidisipliner" menjelaskan bahwasanya perlokusi merupakan suatu hasil dari upaya yang dicapai oleh penutur dalam mengatakan sesuatu, seperti mengahalangi, membujuk, dan meyakinkan (Cummings, 2007). Selaras dengan ini, Greoffrey Leech juga menjelaskan dalam bukunya "The Principles of Pragmatics" bahwasanya tindak perlokusi ialah suatu tindakan dengan mengatakan sesuatu (Leech, 2011). Tindak perlokusi ini dapat diwujudkan melalui ungkapan bahasa atau tindak tutur komunikasi yang bersifat eksersitif, dalam rangka memperingatkan, meyakinkan, merayu, mengarahkan, atau membujuk (Wibowo, 2015).

Di dalam artikel ini, peneliti akan menggunakan teori klasifikasi tindak tutur perlokusi menurut Geoffrey Leech untuk menganalisis dialog dalam web series "Di Balik Hati" tersebut. Leech telah membagi aspek-aspek perlokusi kedalam 16 bagian seperti dibawah ini. Perlokusi: bring $h$ to learn that (membuat t tahu bahwa), persuade (membujuk), deceive (menipu), encourage (mendorong), irritate (menjengkelkan), frighten (menakuti), amuse (menyenangkan), get h to do (membuat t melakukan sesuatu), inspire (mengilhami), impress (mengesankan), distract (mengalih 
Jurnal Pujangga Volume 6, Nomor 2, Desember 2020

ISSN P 2443-1478

ISSN E 2443-148

perhatian), get $h$ to think about (membuat $\mathrm{t}$ berfikir tentang), relieve tension (melegakan), embarrass (mempermalukan), attract attention (menarik perhatian), bore (menjauhkan) (Leech, 2011).

\section{Web Series}

Web series merupakan suatu program acara hiburan melalui tayangan medium yang sedang berkembang di Web TV. Salah satu contoh Web TV yang sedang populer di dunia maya saat ini ialah vimeo dan yotube. Disetiap episodenya memiliki durasi delapan hingga dua puluh menit. Web series memiliki perbedaan jika dibandingkan dengan sinetron dan novel. Sinetron merupakan tayangan televisi yang membutuhkan beberapa episode dan seri atau episode untuk sampai pada ending ceritanya (Marseli, 1996). Sedangkan novel ialah cerita suatu yang dikemas dalam bentuk prosa dengan ukuran yang luas dan memiliki alur cerita yang kompleks (Husman, 1984).

\section{METODE PENELITIAN}

Jenis penelitian dalam penelitian ini adalah penelitian deskriptif kualitatif. Penelitian ini mendeskripsikan serta menggambarkan tindak tutur perlokusi dalam web series "Di Balik Hati" menurut fakta-fakta yang nyata atau tanpa dibuat-buat. Sedangkan kualitatif adalah penelitian yang menghasilkan penemuan-penemuan yang tidak dapat dicapai menggunakan statistik atau dengan cara-cara kuantifikasi lainnya. Melalui metode kualitatif peneliti berusaha mengetahui, memahami, menjelaskan, dan menganalisa dan menghasilkan data deskriptif berupa kata-kata tertulis (Suharsaputra, 2012).

Sumber data merupakan data yang dikumpulkan oleh peneliti baik primer maupun sekunder (Siswanto, 2012). Data primer dalam penelitian ini di dapatkan berasal dari dialog percakapan antar tokoh dalam web series "Di Balik Hati" yang diambil dari channel film maker muslim di youtube. Sedangkan sumber data sekunder dalam penelitian ini diperoleh dari referensi yang mendukung baik itu berupa buku, artikel, maupun jurnal yang bersumber dari internet.

Teknik pengumpulan data adalah prosedur paling krusial dalam sebuah penelitian karena target khususnya untuk memperoleh data yang kridibel (Sugiyono, 2008). Teknik yang dipakai peneliti dalam memperoleh data ialah teknik simak dan catat. Penggunaan teknik simak dengan cara mengamati, menyimak, dan mendengarkan secara seksama media audio visual yaitu web series "Di Balik Hati”. Sementara teknik catat dilakukan untuk mengelompokkan dan menulis tuturan tokoh yang termasuk ke dalam jenis tindak tutur perlokusi dan mengkategorikannya sesuai dengan 16 jenis klasifikasi Geoffrey Leech. 
ISSN P 2443-1478

ISSN E 2443-148

Setelah data valid terkumpul, peneliti akan menganalisis dengan teknik analisis data model Miles dan Huberman. Menurutnya, ada empat kategori tahapan dalam menganalisis data kualitatif, yaitu: pengumpulan data, reduksi data, pemaparan data, dan verifikasi kesimpulan (Sugiyono, 2008).

\section{ANALISIS DAN PEMBAHASAN}

\section{Bentuk Tutur Perlokusi}

Melihat beberapa scene yang terdapat dalam webseries, peneliti menemukan beberapa pola tuturan perlokusi. Suatu tuturan yang diutarakan oleh seseorang dalam upaya untuk mempengaruhi atau memberikan sebuah efek kepada lawan tuturnya (perlocutionary force) (Wijana, Dewa Putu dan Rohmadi, 2011), sebagaimana tuturan dibawah ini:

\section{Episode 1}

Dalam Episode 1 ini, terdapat 2 bentuk tuturan perlokusi yakni tuturan membujuk. Adapun pembahasannya sebagai berikut:

\section{a. Membujuk}

Hari merupakan seorang pekerja kantor yang memiliki jabatan, kemudian ia terlibat percakapan dengan seorang bos yang menawarkan harga murah dari sesuatu yang di inginkannya dari Hari.

Hari : :Iya Pak, emang harganya segitu. Biasanya malah emang lebih mahal”

Bos : :"Apa gak bisa diturunin sedikit saja Har, kemaren ga semahal itu”

Abyad : :Jangan, enak banget nego-nego. Padahal si Bos terima beres aja lo. Gini Har, kamu ini susah payah cari vendor. Jadi perantara, mondar-mandir keluar kota, masa cuma ambil untung seumpet. Lagian cuma beda sedikit dari harga yang biasa dikasih sama kantor. Har. Keluarga kamu butuh uang itu".

Bos : :Halo Har, gimana Har” 
Jurnal Pujangga Volume 6, Nomor 2, Desember 2020

ISSN P 2443-1478

ISSN E 2443-148

Hari : :Gimana ya Pak, berat sih”

Hari yang sedang menanggapi negosiasi harga dari Bosnya dibujuk oleh Setan pengganggu umat yang taat, bergelar Abyad itu. Dia membisiki Hari agar tidak memberikan harga murah pada si Bos. Ditandai dengan bujukan Abyad dalam kalimat panjang "Jangan, enak banget nego-nego „, (dan seterusnya)". Bujukan tersebut membuat Hari melakukan efek perlokusi yakni terbujuk untuk tidak memberikan harga murah pada si Bos. Inilah yang menunjukkan bentuk tuturan perlokusi seperti teori leech.

\section{b. Membujuk}

Kemudian dalam scene yang sama, Abyad masih membujuk Hari yang masih terlibat negosiasi harga dengan si Bos.

Abyad :"Bilang kamu engga ambil untung sedikitpun!”

Hari : "Ini aja saya ..."

Abyad : "Jangan jangan, berlebihan. Bilang untungnya sedikit!"

Hari : "Cuman ambil sedikit keuntungan"

Bos : "Aduuu, banyak pengeluaran saya ini Har"

Hari : "Iya Pak kalau bisa lebih murah, pasti saya kasih Pak"

Penggalan percakapan diatas menunjukkan bahwa Hari tidak dapat bernegisasi. Lantas ia tetap membujuk untuk menjelaskan alasan penolakannya. Adanya kalimat "Jangan jangan, berlebihan. Bilang untungnya sedikit!” kemudian bujukan itu berdampak kepada Hari, ia mengatakan apa yang dikatakan oleh Abyad "Cuman ambil sedikit keuntungan".

\section{Episode 2}

\section{a. Mengesankan (pemikiran)}

Ana adalah seorang mahasiswi yang cerdas, ia mengungkapkan pemikirannya didepan dosen dan teman-temannya saat presentasi di kelas.

Ana : "Sekali lagi hak dan kewajiban perempuan dalam islam bukanlah untuk menunjukkan perbedaan derajat antara laki-laki dan perempuan atau sebaliknya. Islam memandang laki-laki dan perempuan sebagai makhluk 
mulia, dengan derajat yang sama. Yang membedakan adalah kebermanfaatan masing-masing bukan harta, bukan tahta, apalagi rupa. Pria dan wanita bisa mendapatkan tempat terbaik disisinya dengan pengabdian bagi Tuhan lewat ibadah, pengabdian bagi dunia lewat mu'amalah. Saya Annisa Fatimah Azzahra. Terimakasih. Wassalamualaikum Warohmatullahi Wabarakatuh".

Dosen : “Cakep kan. Begitu. Wanita muslimah harus cerdas, harus berwawasan luas, dan pandai mengungkapkan pemikiran mereka. Bagus sekali Ana. Terimakasih"

Mahasiswa : (tepuk tangan).

Penggalan percakapan diatas menggambarkan bahwa sosok Ana sedang mengungkapkan pemikirannya di depan teman-temannya dan dosen. Pemikiran Ana sangat mengesankan karena dapat membuat seseorang merasa kagum. Dalam konteks ini, dampak yang diberikan berupa apresiasi dosen dengan pertanyaan "Cakep kan. Begitu. Wanita muslimah harus cerdas, harus berwawasan luas, dan pandai mengungkapkan pemikiran mereka. Bagus sekali Ana. Terimakasih". Ini menjelaskan bahwa suatu tuturan yang diutarakan oleh seseorang dalam upaya untuk mempengaruhi atau memberikan sebuah efek kepada lawan tuturnya (perlocutionary force) (Wijana, Dewa Putu dan Rohmadi, 2011).

\section{Episode 3}

\section{a. Membuat petutur tahu}

Seusai pingsan diperpustakaan, Ana dibawa ke UKS. Kemudan ia sadar, dan kembali menemui sosok Abyad disampingnya. Ia kembali pingsan, akhirnya sadar kembali dan terlibat percakapan dengan Abyad.

Abyad :"Buat saya ini juga aneh, biasanya manusia tidak bisa melihat kami”

Ana :"Kami?"

Abyad :"Saya ini setan!”

Ana : :Hah?”

Penggalan percakapan diatas, menimbulkan dampak secara perlokusi terhadap Ana mengetahui bahwa Abyad adalah setan. Hal ini sejalan dengan teori Leech yang memaparkan 
Jurnal Pujangga Volume 6, Nomor 2, Desember 2020

ISSN P 2443-1478

ISSN E 2443-148

bahwa tuturan perlokusi adalah suatu tuturan yang diutarakan oleh seseorang dalam upaya untuk mempengaruhi atau memberikan sebuah efek kepada lawan tuturnya (perlocutionary force) (Wijana, Dewa Putu dan Rohmadi, 2011).

\section{b. Membuat petutur berpikir akan sesuatu}

Karena masi terlibat percakapan yang cukup serius. Lagi-lagi Ana masih belum percaya, apalagi ketika Abyad mengatakan bahwasanya ia telah hidup selama 500 tahun.

Abyad : "Saya juga penasaran, 500 tahun lebih saya hidup baru kali ini ada manusia bisa lihat saya!"

Ana : "Masa 500 tahun? wajahnya engga tua. Kayak 20 tahunan!"

Abyad : "Karna saya bukan manusia saya setan dari golongan jin"

Ana : "Jadi jin apa setan?"

Abyad : "Setan itu dari gologan jin dan manusia, nah saya ini setan dari golongan jin. Kamu ini baca Al Qur'an atau tidak sih!”

Ana : (kemudian Ana kembali bertanya perihal setan lebih jauh kepada Abyad ditaman).

Karena terlibat percakapan yang serius, dan dari pengakuan Abyad yang jelas disertai alasan. Efek perlokusi yang dihasilkan adalah Ana dibuat bertanya-tanya dan lebih dalam memikirkan apa yang dikatakan Abyad sejak kali pertama berbicara dengannya. Ditandai dengan pertanyaan-pertanyaan tentang setan yang ia lontarkan kepada Abyad selepas dari UKS. Hal ini sejalan dengan teori Leech yang memaparkan bahwa tuturan perlokusi adalah suatu tuturan yang diutarakan oleh seseorang dalam upaya untuk mempengaruhi atau memberikan sebuah efek kepada lawan tuturnya (perlocutionary force) (Wijana, Dewa Putu dan Rohmadi, 2011).

\section{Episode 4}

\section{a. Mengalihkan perhatian}

Dikronologikan bahwa Ana tengah mendengarkan dengan seksama penjelasan dari dosen, kemudian Abyad yang duduk disampingnya mencoba mengganggu Ana dengan mengatakan halhal yang menurutnya dapat mempengaruhinya agar jenuh.

Abyad : "Kamu tidak bosan?" 
Jurnal Pujangga Volume 6, Nomor 2, Desember 2020

ISSN P 2443-1478

ISSN E 2443-148

Ana : (melirik sekilas kemudian kembali mendengarkan)

Abyad : "Kegiatan harian manusia itu betul-betul menyengsarakan ya, kalian ikuti aturan dosen, aturan orang tua, aturan masyarakat, aturan Tuhan"

Ana : "Kamu bisa diem gak!" (membentak)

Usaha Abyad untuk mengganggu Ana tak membuahkan hasil, justru membuat Ana marah dengan membentaknya. Efek perlokusi yang di hasilkan adalah Ana membentak Abyad, seraya berkata "Kamu bisa diem gak?”. Hal ini sejalan dengan teori Leech yang memaparkan bahwa tuturan perlokusi adalah suatu tuturan yang diutarakan oleh seseorang dalam upaya untuk mempengaruhi atau memberikan sebuah efek kepada lawan tuturnya (perlocutionary force) (Wijana, Dewa Putu dan Rohmadi, 2011).

\section{b. Membuat petutur melakukan sesuatu}

Ketika di kantin, Abyad menghampiri Ana yang tengah duduk membaca buku. Abyad memberitahu bahwasanya ada seorang laki-laki yang rajin ibadah dibelakang mereka sedang digoda oleh bangsa setan untuk mencuri.

Abyad : "Kamu lihat manusia disana!"

Ana : "Jangan nunjuk-nunjuk, gaenak di ... apa?"

Abyad : "Dia sudah kehabisan cara untuk bayar semester, dan menurut simtem pendidikan kalian, dia tidak layak mengikuti ujian. Kamu tau aslinya dia seorang mahasiswa yang rajin beribadah, taat pada aturan, tapi sepertinya akhir-akhir ini dia merasa dikecewakan oleh Tuhan. Ibunya sakit keras, adikadiknya pun belum bayar uang sekolah. Dia pun begitu, sudah satu minggu ini dia dibisiki oleh Abyad. Satu..... dua... tiga..."

(pemuda itupun memulai aksinya)

Ana : (mengejar pemuda itu)

Penggalan percakapan diatas menunjukkan bahwa tatkala Abyad memberitahu permasalahan hidup pemuda tersebut, Ana pun mendengarkan. Usai bercerita, Abyad berhitung "Satu... dua... tiga..." menandakan si pemuda tersebut akan melakukan sesuatu aksi. Dan efek perlokusi yang dihasilkan adalah Ana mengejar pemuda itu untuk mencegahnya dari melakukan 
Jurnal Pujangga Volume 6, Nomor 2, Desember 2020

ISSN P 2443-1478

ISSN E 2443-148

perbuatan dosa. Hal ini sejalan dengan teori Leech yang memaparkan bahwa tuturan perlokusi adalah suatu tuturan yang diutarakan oleh seseorang dalam upaya untuk mempengaruhi atau memberikan sebuah efek kepada lawan tuturnya (perlocutionary force) (Wijana, Dewa Putu dan Rohmadi, 2011).

\section{Episode 5}

\section{a. Membuat petutur tahu atau belajar tentang sesuatu}

Digambarkan dalam scene ini, lontaran pertanyaan dari Ana yang masih penasaran dengan kehidupan bangsa setan, terjawab oleh Abyad.

Abyad : "Ini namanya buah dosa, kami butuh ini sebagai makanan kami, ini bisa dipanen dari manusia yang memilih untuk berbuat dosa"

Ana : "Maksudnya?"

Abyad : "Pada dasarnya fitrah manusia adalah melakukan kebajikan, kecuali mereka yang gagal mengendalikan nafsunya. Kami menggoda manusia yang pintu hatinya tertutup, mencari celah agar bisa mendapatkan buah dari dosa kalian. Tapi, kadang manusia punya iman yang kuat"

Ana : "Terus, kalau kalian gagal menggoda manusia, kalian engga akan dapat buah dosa?"

Abyad : "Kami tidak menyerah sampai manusia dapat mengikuti langkah kami, langkah iblis"

Dari jawaban Abyad sebagai penutur, menghasilkan efek kepada Ana yakni ia dapat mengetahui lebih dalam tentang kehidupan bangsa setan dan sekaligus mempelajari sesuatu yang belum ia ketahui. Hal ini sejalan dengan teori Leech yang memaparkan bahwa tuturan perlokusi adalah suatu tuturan yang diutarakan oleh seseorang dalam upaya untuk mempengaruhi atau memberikan sebuah efek kepada lawan tuturnya (perlocutionary force) (Wijana, Dewa Putu dan Rohmadi, 2011).

\section{b. Menjengkelkan}

Digambarkan dalam scene ini, seorang Firman terjebak macet yang cukup padat. Disisi lain, ibu Ana menelfonnya karena ia sedang menunggu kedatangan Firman. Dalam kesabarannya 
Jurnal Pujangga Volume 6, Nomor 2, Desember 2020

ISSN P 2443-1478

ISSN E 2443-148

itu setan menggodanya agar ia melakukukan dosa yakni berbohong. Namun, lagi-lagi imannya tak tergoyahkan. Ia tetap jujur pada ibu Ana atas apa yang ditanyakan padanya.

Setan : :Kan, udah bohong aja, udah bilang aja tadi ada urusan dulu. Bohong sedikit kan tidak ada dosanya"

Firman : "Iya tadi Firman berangkatnya juga agak telat, insha Allah lepas macet ini Firman melesat"

Ibu : "Oh yasudah, Ibu tunggu ya"

Setan : "Manusia sok suci!!!"

Dalam hal ini, setan merasa gagal membuat Firman melakukan dosa. Di atas ini, adalah bisikan kesekian kalinya yang diupayakan oleh setan, ditandai dengan bisikan "Kan, udah bohong aja, uda bilang aja tadi ada urusan dulu. Bohong sedikit kan tidak ada dosanya", namun bisikan itu tetap gagal. Kemudian setan merasa jengkel, dapat dilihat dari mimik muka dan teriakannya “Manusia sok suci!!!”. Hal ini sejalan dengan teori Leech yang memaparkan bahwa tuturan perlokusi adalah suatu tuturan yang diutarakan oleh seseorang dalam upaya untuk mempengaruhi atau memberikan sebuah efek kepada lawan tuturnya (perlocutionary force) (Wijana, Dewa Putu dan Rohmadi, 2011).

\section{Epiosde 6}

\section{a. Menyakitkan}

Pagi itu, berkumpul bersama dalam ruang tamu, Firman, Ana dan Ibunya. Kemudian Firman mengatakan niatnya untuk melamar Ana. Abyad pun yang hampir setiap hari bersama Ana, ikut berkumpul dan mendengarkan. Namun hanya Ana yang dapat melihatnya. Ketika Firman mengungkapkan hal tersebut, Abyad bermuka masam.

Ibu : "Kalau boleh tau, maksud dan kedatangan nak Firman datang kesini itu apa?"

Firman : "Ada hubungannya dengan janji orang tua Firman Tante"

Ibu : "Apa tu?"

Firman : "Firman mau melamar Ana" 
Jurnal Pujangga Volume 6, Nomor 2, Desember 2020

ISSN P 2443-1478

ISSN E 2443-148

(Abyad bermuka masam, dan sepertinya kesal)

Saat Firman berkata "Firman mau melamar Ana", Abyad terkejut dan ia mulai bermuka masam. Yang kemudian ia juga bertanya kembali pada Ana dengan mimik lesu, setelah kepergian Firman “Jadi kamu akan menikah?”. Efek perlokusi dari scene ini Abyad sedih mendengar apa yang diungkapkan oleh Firman. Hal ini sejalan dengan teori Leech yang memaparkan bahwa tuturan perlokusi adalah suatu tuturan yang diutarakan oleh seseorang dalam upaya untuk mempengaruhi atau memberikan sebuah efek kepada lawan tuturnya (perlocutionary force) (Wijana, Dewa Putu dan Rohmadi, 2011).

\section{b. Menipu}

Pak Saib adalah seorang yang berkekurangan. Saat di masjid, ia memandangi kotak amal yang berada di pelataran teras masjid. Abyad menghampiri dan membisiki pak Saib, agar ia mencuri uang dalam kotak amal itu.

Abyad : "Aneh kan, kamu jelas jelas lebih membutuhkan, kamu jelas - jelas masuk dalam kategory mustad'afin, orang kecil, orang tertindas. Tapi lihat orang orang beriman ini, ada mereka melirik kamu? Lihat manusia satu ini, baju kokonya saja mungkin ratusan ribu. Lihat jam tangannya, coba lihat, dia lebih peduli penampilannya dibanding orang orang yang membutuhkan seperti kamu. Disini ada hak kamu, hak orang-orang yang diberi ujian oleh Tuhan. Tuhan titipkan hak kamu kepada orang-orang ini, tetapi mereka tidak mau menyampaikan kepadamu. Jadi bukan dosa kalau kamu ambil apa yang seharusnya milik kamu"

Pak Saib : (mulai mengambil)

Abyad membisikinya dengan kalimat panjang, yang ditandai dengan kalimat "Aneh kan, kamu jelas-jelas lebih membutuhkan ... (dan seterusnya). Efek perlokusinya, pak Saib tertipu oleh muslihat Abyad, ia mempercayai kepada sesuatu yang tidak benar yakni ketika Abyad mengatakan bahwa “Jadi bukan dosa kalau kamu ambil apa yang seharusnya milik kamu”. Kemudian pak Saib memulai aksinya. Hal ini sejalan dengan teori Leech yang memaparkan bahwa tuturan perlokusi adalah suatu tuturan yang diutarakan oleh seseorang dalam upaya untuk mempengaruhi atau memberikan sebuah efek kepada lawan tuturnya (perlocutionary force) (Wijana, Dewa Putu dan Rohmadi, 2011). 
ISSN P 2443-1478

ISSN E 2443-148

\section{c. Membuat petutur berfikir sesuatu}

Berlanjut dari scene di atas, ketika pak Saib memulai aksinya, tiba-tiba Ana menghampiri. Dan menyodorkan amplop kepada pak Saib. Agar supaya pak Saib tidak jadi mencuri dan merasa terbantu dengan adanya uang dalam amplop tersebut.

Ana : "Ini ada titipan buat Bapak"

Pak Saib: "Buat saya? Dari siapa?"

Ana : "Dari orang yang nggak mau Bapak menyerah"

Pak Saib: (keheranan, berfikir siapa yang memberi)

Saat Pak Saib bertanya “Dari siapa?”, kemudian Ana menjawab “Dari orang yang nggak mau Bapak menyerah”. Lalu, ungkapan itulah yang membuat pak Saib terlihat bertanya-tanya siapa yang memberikan amplop tersebut, tampak dari mimik mukanya. Jadi, efek perlokusi yang di hasilkan membuat pak Saib berfikir tentang siapa yang memberikan amplop tersebut. Hal ini sejalan dengan teori Leech yang memaparkan bahwa tuturan perlokusi adalah suatu tuturan yang diutarakan oleh seseorang dalam upaya untuk mempengaruhi atau memberikan sebuah efek kepada lawan tuturnya (perlocutionary force) (Wijana, Dewa Putu dan Rohmadi, 2011).

\section{Episode 7}

\section{a. Menipu}

Eva adalah salah seorang sahabat Ana, ia memutuskan untuk memakai jilbab. Namun, setan perempuan teman Abyad membisikinya kalimat-kalimat tipu daya, agar ia menunda untuk memakai jilbab.

Setan : “Aduuh berat loh kalo mau pake jilbab, apalagi kalo hatimu belum siap, nanti orang-orang akan bilang kamu kerudung dusta kalo kamu melakukan keburukan. Sedikit saja kamu melakukan keburukan, maka cap munafik akan melekat dan sulit dilepas"

Eva : "Eva kamu pakai jilbab untuk dirimu sendiri, untuk kebaikan kamu"

Setan : "Iya emang untuk dirimu, tapi orang-orang tidak berfikir begitu. Inget Eva, sekali kamu memakai jilbab, maka saat itu kamu mempunyai tanggung jawab besar, lebih baik kamu benahi dulu akhlakmu, sampai kamu pantas 
menggunakan jilbab, iyakan? Kamu pakai jilbab nanti-nanti juga belum terlambat kan, Tuhan itu maha pemaaf.

Penggalan percakapan di atas menunjukkan bahwa Setan perempuan menggoda Eva dengan tuturan "Aduuh berat loh kalo mau pake jilbab (dan seterusnya) serta kalimat kedua "Iya emang untuk dirimu, tapi orang-orang tidak berfikir begitu... (dan seterusnya) yang mengakibatkan Eva menunda untuk memakai jilbab. Hal ini sejalan dengan teori Leech yang memaparkan bahwa tuturan perlokusi adalah suatu tuturan yang diutarakan oleh seseorang dalam upaya untuk mempengaruhi atau memberikan sebuah efek kepada lawan tuturnya (perlocutionary force) (Wijana, Dewa Putu dan Rohmadi, 2011).

\section{b. Mengilhami}

Eva yang telah menunda dirinya untuk memakai hijab diberi pertanyaan oleh Ana. Mungkin diniatkan agar Eva terlebih dulu mengetahui esensi dari pemakaian hijab

Ana : "Va, sini deh aku kasih tau. menurutmu kenapa seorang muslimah pakai jilbab?"

Eva : "Untuk jaga aurat? Eh salah, untuk membantu laki-laki menundukkan pandangan $\mathrm{Va} "$

Ana : "Karena perintah Allah Va"

(kemudian saling berpelukan)

Setelah diberi pertanyaan Eva menjawab, namun jawabannya kurang tepat. Kemudian Ana menjawab, ditandai dengan kalimat "Karena perintah Allah Va”. Tidak sekedar bertujuan untuk menjaga aurat dan membantu laki-laki menundukkan pandangan. Memakai hijab sebenarnya adalah karena perintah Allah. Kalimat yang dilontarkan Ana memiliki Efek perlokusi. Eva merasa terilhami dengan alasan yang di katakan oleh Ana, kemudian kebesokannya ia mulai mengenakan jilbab. Hal ini sejalan dengan teori Leech yang memaparkan bahwa tuturan perlokusi adalah suatu tuturan yang diutarakan oleh seseorang dalam upaya untuk mempengaruhi atau memberikan sebuah efek kepada lawan tuturnya (perlocutionary force) (Wijana, Dewa Putu dan Rohmadi, 2011).

\section{Episode 8}

\section{a. Membuat petutur tahu atau belajar tentang sesuatu}


ISSN P 2443-1478

ISSN E 2443-148

Dikronologikan, seorang Ana keluar rumah untuk pergi kuliah. Ana mendapati pak Man yang kelihatannya memulung di tempat sampah rumah depan rumah Ana. Setelah Ana menyapa pak Man ia lantas meneruskan perjalanannya. Belum jauh, Abyad muncul.

Abyad : (mengangguk)

Ana : "Ada yang bisikin Pak Man, siapa?"

Abyad : "Tsabur setan yang menggoda orang-orang yang terkena musibah"

Ana : "Jadi Pak Man sedang ditimpa musibah?"

Penggalan percakapan diatas menunjukkan bahwa Abyad memberi tahu Ana bahwa ada setan yang menggoda Pak Man ditandai dengan kalimat "Tsabur setan yang menggoda orangorang yang terkena musibah" dalam hal ini Abyad telah memberi tahu 2 hal, yakni tentang Pak Man yang didera musibah dan setan yang membisikinya untuk mencuri di rumah Ana. Efek perlokusinya, Ana menjadi tahu informasi tersebut. Hal ini sejalan dengan teori Leech yang memaparkan bahwa tuturan perlokusi adalah suatu tuturan yang diutarakan oleh seseorang dalam upaya untuk mempengaruhi atau memberikan sebuah efek kepada lawan tuturnya (perlocutionary force) (Wijana, Dewa Putu dan Rohmadi, 2011).

\section{b. Mendorong}

Masih dalam scene yang sama. pak Man merasa senang karena telah diberikan pekerjaan oleh ibu Ana. Merasa diberi harapan oleh ibu Ana dan merasa diberi dukungan oleh Ana.

Pak Man : "Ibuk, sama Neng Ana. Beneran saya boleh kerja ditempat Ibu?"

Umi Ana : "Boleh Pak. Tapi Pak Man janji harus amanah.Ya!"

Ana : "Semangat Pak!"

Pak Man : "Iya Neng, Alhamdulillah"

Kalimat dorongan yang terdapat dalam scene dialog di atas ditandai dengan kalimat “Semangat Pak!'” yang dikatakan Ana kepada pak Man. Dan pak Man merasa terdukung dengan kalimat tersebut, kemudian berkata “Iya neng, Alhamdulillah”. Hal ini sejalan dengan teori Leech yang memaparkan bahwa tuturan perlokusi adalah suatu tuturan yang diutarakan oleh seseorang dalam upaya untuk mempengaruhi atau memberikan sebuah efek kepada lawan tuturnya (perlocutionary force) (Wijana, Dewa Putu dan Rohmadi, 2011). 
ISSN P 2443-1478

ISSN E 2443-148

\section{Episode 9}

\section{a. Meredakan ketegangan}

Ternyata setan taman Abyad itu memiliki tujuan mengapa ia berada dalam mobil juga. Ia ingin membisiki kesenangan pada Firman, ia memanfaatkan rasa kasmaran yang Firman alami saat itu agar berbelok pada perbuatan yang dilarang Allah.

Abyad : "Ana kamu dengar saya berbicara, saat ini ada setan lain disini. Dia mengejar Firman, saya tidak tahu untuk apa, tapi kamu harus minta dia untuk hati-hati!"

(dialog sengit antara Abyad dan temannya)

Abyad : "Tenang Ana, apapun yang terjadi saya akan melindungi kamu”

Ana : (mengangguk)

Abyad mengatakan pada Ana bahwa temannya mempunyai muslihat untuk menggoda Firman. Ia tidak tahu persis apa yang akan di lakukan temannya itu, kemudian Abyad menenangkan Ana seraya meminta Ana agar mengatakan pada Firman untuk berhati-hati. Kalimat penenangnya ialah yang dilontarkan oleh Abyad "Tenang Ana, apapun yang terjadi saya akan melindungi kamu”. Hal ini sejalan dengan teori Leech yang memaparkan bahwa tuturan perlokusi adalah suatu tuturan yang diutarakan oleh seseorang dalam upaya untuk mempengaruhi atau memberikan sebuah efek kepada lawan tuturnya (perlocutionary force) (Wijana, Dewa Putu dan Rohmadi, 2011).

\section{b. Membuat petutur melakukan sesuatu}

Untuk memulai muslihatnya, teman Abyad itu menyuruh Abyad menyusul Ana. Agar supaya ia dapat membisiki Firman dengan leluasa.

Setan : "Kejar ... ! yang menurutmu bisa menolong mereka"

Abyad : (menyusul Ana dikamar ke toilet)

Tak butuh berfikir lama, ketika Abyad dibisiki oleh temannya dengan kalimat "Kejar ... ! yang menurutmu bisa menolong mereka”. Abyad pun langsung menghilang untuk menyusul, dan mengatakan sesuatu kepada Ana. Hal ini sejalan dengan teori Leech yang memaparkan bahwa 
Jurnal Pujangga Volume 6, Nomor 2, Desember 2020

ISSN P 2443-1478

ISSN E 2443-148

tuturan perlokusi adalah suatu tuturan yang diutarakan oleh seseorang dalam upaya untuk mempengaruhi atau memberikan sebuah efek kepada lawan tuturnya (perlocutionary force) (Wijana, Dewa Putu dan Rohmadi, 2011).

\section{PENUTUP}

\section{Simpulan}

Dari pembahasan di atas ditemukan tuturan perlokusi sebanyak 23 tuturan dengan perincian sebagai berikut: Membuat petutur tahu atau belajar tentang sesuatu sebanyak 5 tuturan, membujuk 2 tuturan, menipu 2 tuturan, mendorong 1 tuturan, menjengkelkan 1 tuturan, menyakitkan 1 tuturan, membuat petutur melakukan sesuatu sebanyak 5 tuturan, mengilhami 1 tuturan, mengesankan 1 tuturan, mengalihkan perhatian 1 tuturan, membuat petutur berpikir akan sesuatu 2 tururan, meredakan ketegangan 1 tuturan. Berdasarkan uraian analisis data diatas, tuturan perlokusi paling banyak dalam web series "Di Balik Hati" adalah tuturan membuat petutur melakukan sesuatu. Adapun tuturan menakuti, menghibur, memalukan, menarik perhatian, dan membosankan adalah tuturan yang ditemukan dalam web series ini.

\section{Saran}

Melihat hasil penelitian ini, peneliti berharap ada penelitian lanjutan mengenai dampak dari tayangan web series bagi aspek sosial seserang atau dari kacamata semiotika agar dapat menemukan kajian lebih mendalam mengenai web series itu sendiri. Selain itu penelitian ini hanya terbata pada kajian pragmatik yang berfokus pada mitra tutur dan pengaruh sebuah tuturan, sehingga perlu ada perspektif lain yang mengkaji web series. 


\section{DAFTAR PUSTAKA}

Arifin, E. Z. (2018). Beragam Tuturan Dalam Pembicaraan Sehari-Hari: Suatu Tinjauan Etnografi Komunikasi. Jurnal Pujangga, 4, no, 1-18.

Cummings, L. (2007). Pragmatik Sebuah Perspektif Muldidisipliner. Pustaka Belajar.

Darwowidjojo, S. (2008). Psikolinguitik: Pengantar Pemahaman Bahasa Manusia (cet. ketig). Yayasan Obor Indonesia.

Erlangga, M. (2014). tren web series indonesia semakin kreatif. Daily Social. https://dailysocial.id/post/tren-web-series-indonesia-semakin-kreatif

Husman, E. (1984). Apresiasi Sastra Indonesia. Angkasa.

Leech, G. (2011). Prinsip-prinsip Pragmatik. Universitas Indonesia-Press.

Marseli, S. (1996). Dasar-Dasar Apresiasi Film. PT. Grasindo.

Pratomo, Y. (2019). apjii jumlah pengguna internet di indonesia tembus 171 juta jiwa. Kompas.Com. https://tekno.kompas.com/read/2019/05/16/03260037/apjii-jumlahpengguna-internet-di-indonesia-tembus-171-juta-jiwa

Siswanto, V. A. (2012). Strategi dan Langkah-langkah Penelitian. Graha Ilmu.

Sugiyono. (2008). Metode Penelitian Pendidikan Pendekatan Kuantitatif, Kualitatif, R\&D. Alfabeta.

Suharsaputra, U. (2012). Metode Penelitian Kuantitatif, Kualitatfs, dan Tindakan. Refika Aditama.

Wibowo, W. (2015). Konsep Tindak Tutur Komunikasi. Bumi Aksara.

Widiatmoko, B. \& waslam. (2017). Interjeksi Dalam Bahasa Indonesia: Analisis Pragmatik. Jurnal Pujangga, 3, no, 83-97.

Wijana, Dewa Putu dan Rohmadi, M. (2011). Analisis Wacana Pragmatik Kajian Teori dan Analisis (cet. ketig). Yuma Presindo. 